\title{
Cumulative Effect of Crumb Rubber and Steel Fiber on the Flexural Toughness of Concrete
}

\author{
Badorul Hisham Abu Bakar \\ School of Civil Engineering \\ Universiti Sains Malaysia, \\ Engineering Campus \\ Penang, Malaysia \\ cebad@usm.my
}

\author{
Ahmed Tareq Noaman \\ School of Civil Engineering \\ Universiti Sains Malaysia, \\ Engineering Campus \\ Penang, Malaysia \\ atn_en@yahoo.com
}

\author{
Hazizan Md. Akil \\ School of Materials and Mineral \\ Resources Eng., Universiti Sains \\ Malaysia, Engineering Campus \\ Penang, Malaysia \\ hazizan@usm.my
}

\begin{abstract}
Concrete properties, such as toughness and ductility, are enhanced to resist different impacts or blast loads. Rubberized concrete, which could be considered a green material, is produced from recycled waste tires grinded into different crumb rubber particle sizes and mixed with concrete. In this study, the behavior of rubberized steel fiber-reinforced concrete is investigated. Flexural performance of concrete beams $(400 \times 100 \times 100 \mathrm{~mm})$ manufactured from plain, steel fiber, crumb rubber and combination crumb rubber and steel fiber are also evaluated. Similarly, concrete slabs $(500 \times 500 \times 50 \mathrm{~mm})$ are also tested under flexural loading. Flexural performance of the SFRRC mixtures was significantly enhanced. The toughness and maximum deflection of specimens with rubber were considerably improved. Steel fiber/crumb rubber-reinforced concrete can be used for practical application, which requires further studies.
\end{abstract}

Keywords-rubberized steel fiber; toughness; flexural behavior

\section{INTRODUCTION}

Resistance of concrete structures against the effects of impact loading, which may suddenly occur, has been the focus of considerable attention. Concrete properties, such as toughness and ductility, are tuned to enhance the resistance against different impact or blast loads. Various studies have enhanced these properties by utilizing natural or artificial waste products to improve the toughness of cement composite or concrete [1-3]. Rubberized concrete could be considered a green material produced by recycling waste tires from different crumb rubber particles and mixed with concrete by replacing a specified portion of aggregate. Public disposal of waste tires has posed serious environmental concern. The combination of these tires with concrete as partial replacement of aggregate presents a potential solution to the environmental problem, beside the other innovative techniques used to recycle them in civil engineering [4].

Crumb rubber concrete exhibits reduced mechanical properties depending on their content [5, 6]. However, in [7] it was observed that concrete toughness and ductility are enhanced because of the ability of rubber aggregate to deform after failure. Rubber crumbs were incorporated into concrete mixture at various volumetric replacement ratios from $5 \%$ to
$20 \%$ of the coarse aggregate. The damping ratio was determined for the concrete column from free vibration test. Rubberized concrete columns showed better performance than normal concrete due to enhancement in damping ratios by about 3\%. This characteristic indicates that concrete containing crumb rubber aggregate is more capable to dissipate kinetic energy.

Rubberized concrete may be used in various civil engineering applications, such as blast walls, bollards, and road traffic barriers, in which the design strength is not a critical parameter. Rubber combined with steel fiber is an innovative material with high tensile properties. In [8], authors evaluated the post-cracking performances of recycled steel fibers from waste tires concrete by testing flexural beams and slabs. The post-cracking behavior of recycled steel fiber reinforced concrete showed reduced brittle behavior, which indicates that more energy is absorbed and that toughness can be possibly increased by more than $100 \%$. Waste recycled rubber interacts with steel fibers and bonds with cement paste such that the steel fiber in the waste recycled rubber also increases concrete deformability under applied loads [9]. Thus, the flexural performances of rubberized and rubberized steel fiber concrete beams were analyzed experimentally. The effect of crumb rubber inclusion as partial replacement of fine aggregate volume at three different ratios, namely, $17.5 \%, 20 \%$, and $22.5 \%$, into plain concrete (PC) was investigated. Similar ratios of crumb rubber were combined with the steel fiber concrete (SFC) mixture. Finally, flexural tests on rubberized concrete slabs were conducted to determine their flexural properties.

\section{EXPERIMENTAL PROGRAM}

\section{A. Materials and mix design}

The mixture used in this study was prepared to achieve concrete compressive strength of $45 \mathrm{MPa}$ on day 28 . Ordinary Portland cement, crushed aggregate from local source with maximum aggregate size of $14 \mathrm{~mm}$, and natural river sand as fine aggregate were used in this work. Crumb rubber was produced by grinding waste tires to produce the desired size in this study $(0.15-2.36 \mathrm{~mm})$. The properties of fine and coarse 
aggregate and crumb rubber aggregate are listed in Table I. Figure 1 shows the recycled crumb rubber particles adapted for the experiments. Steel fiber (hooked-end bundled) with aspect ratio of 80 , circular diameter of $0.75 \mathrm{~mm}$, specific gravity of 7.85 , and tensile strength of $1050 \mathrm{MPa}$ is used, as shown in Figure 1. A polycarboxylic (ether-based) superplasticizer (SP) was used to enhance the low workability of the SFC mixtures.

TABLE I. PROPERTIES OF NATURAL AGGREGATE AND CRUMB RUBBER

\begin{tabular}{|c|c|c|c|c|c|}
\hline $\begin{array}{c}\text { Type of } \\
\text { aggregate }\end{array}$ & $\begin{array}{c}\text { Specific } \\
\text { gravity }\end{array}$ & Absorption\% & $\begin{array}{c}\text { Moisture } \\
\text { content\% }\end{array}$ & $\begin{array}{c}\text { Fineness } \\
\text { modulus }\end{array}$ & $\begin{array}{c}\text { Specific } \\
\text { area } \\
\mathbf{m m}^{2} / \mathbf{g}\end{array}$ \\
\hline Coarse & 2.65 & 1.0 & 1.0 & 6.27 & $\mathrm{NA}$ \\
\hline Fine & 2.64 & 2.0 & 3.0 & 3.93 & 0.672 \\
\hline rubber & 0.73 & 10.6 & 1.4 & $\mathrm{NA}$ & 0.774 \\
\hline
\end{tabular}

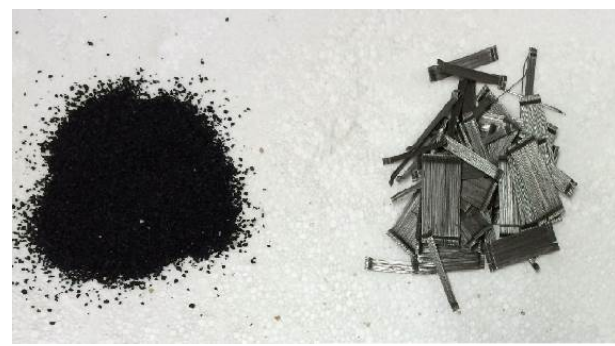

Fig. 1. Crumb rubber and steel fiber.

Concrete mixtures were prepared with different replacement ratios of fine river sand volume by crumb rubber particles. The replacement ratios were $17.5 \%, 20 \%$, and $22.5 \%$, and the corresponding samples were designated as CR17.5, CR20, and CR22.5. The SFC mixture was considered a reference mix without crumb rubber. The volume fraction of the steel fiber was fixed $(0.5 \%)$. Rubberized steel fiber reinforced concrete mixtures were prepared by adding crumb rubber at the same replacement ratios for rubberized concrete (i.e., $17.5 \%, 20 \%$, and $22.5 \%$ ), and the corresponding samples were denoted as SFCR17.5, SFCR20, and SFCR22.5. Plain (PC), Steel fiber (SFC) concrete mixtures, and mix proportions are presented in Table II. Other mixtures, such as rubberized and rubberized steel fiber. Compositions of concrete mixes are presented in Tables III and IV, respectively. For all mixes water/cement ratio was fixed $=0.47$.

\section{EXPERIMENTAL DETAILS AND PROCEDURES}

\section{A. Compressive strength test}

Compressive strength tests were conducted using three cubes with $100 \mathrm{~mm}$ sides in accordance with the British standard BS 1881: Part 116 [10] on three cubic specimens for each mixture, using an oil hydraulic machine with a capacity of $3,000 \mathrm{kN}$. The compressive strength was calculated from the measured load over the area of the cube.

\section{B. Four-point bending test}

Four-point bending tests were carried out on the rubberized steel fiber beams to investigate the effect of combination between crumb rubber and steel fiber on the flexural performance of concrete. The flexural test setup and specimen geometry are illustrated in Figure 2. Three beams of each type of mixture were prepared for this test. The beams were $100 \mathrm{~mm}$ wide, $100 \mathrm{~mm}$ deep, and $400 \mathrm{~mm}$ long, with loaded span of 300 mm.The experimental setup is in accordance with ASTM C1609 [11]. The test was carried out using a $100 \mathrm{kN}$ AG-X series Shimadzu Universal Testing Machine. The concrete specimens were loaded to ultimate failure under constant displacement rate at a loading rate of $0.1 \mathrm{~mm} / \mathrm{min}$. The loads versus mid-span deflection data were recorded, and the modulus of rupture (MOR) was calculated. Three specimens from each mixture were tested for 28 days.

TABLE II. CONCRETE MIX DESIGN FOR PLAIN AND STEEL FIBER MIXTURES

\begin{tabular}{|c|c|c|c|c|}
\hline Mix & Cement & Steel fiber & $\begin{array}{c}\text { Coarse } \\
\text { aggregate }\end{array}$ & $\begin{array}{c}\text { Fine } \\
\text { aggregate }\end{array}$ \\
\hline PC & 430 & 0 & 907 & 814 \\
\hline SFC & 430 & 39 & 907 & 814 \\
\hline
\end{tabular}

TABLE III. CONCRETE MIX DESIGN FOR RUBBERIZED MIXTURES

\begin{tabular}{|c|c|c|c|c|}
\hline Mix & Cement & $\begin{array}{c}\text { Coarse } \\
\text { aggregate }\end{array}$ & $\begin{array}{c}\text { Fine } \\
\text { aggregate }\end{array}$ & Rubber \\
\hline CR17.5\% & 430 & 907 & 670 & 39.5 \\
\hline CR20\% & 430 & 907 & 649 & 45.3 \\
\hline
\end{tabular}

TABLE IV. CONCRETE MIX DESIGN FOR STEEL FIBER REINFORCED RUBBERIZED MIXTURES

\begin{tabular}{|c|c|c|c|c|c|}
\hline Mix & Cement & $\begin{array}{c}\text { Steel } \\
\text { fiber }\end{array}$ & $\begin{array}{c}\text { Coarse } \\
\text { aggregate }\end{array}$ & $\begin{array}{c}\text { Fine } \\
\text { aggregate }\end{array}$ & Rubber \\
\hline SFRC17.5\% & 430 & 39 & 907 & 670 & 39.5 \\
\hline SFRC20\% & 430 & 39 & 907 & 649 & 45.3 \\
\hline SFRC22.5\% & 430 & 39 & 907 & 630 & 50.3 \\
\hline
\end{tabular}

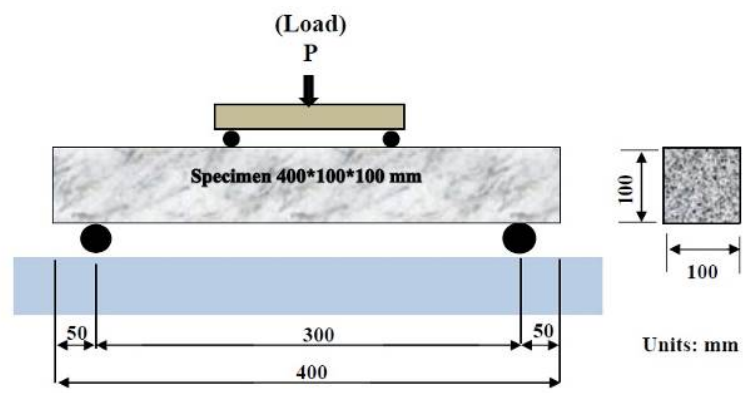

Fig. 2. Test set-up for the four-point bending test.

\section{Flexura test of slabs}

Square slabs with dimensions of $500 \times 500 \times 50 \mathrm{~mm}$ were prepared to investigate their behavior under static loading. The tested slabs were fixed on the built-in testing machine after 28 days of moist curing (Figure 3). Slab specimens were placed on steel supports consisting of four rollers supported by four-sided rigid square steel hollow tubes. The span between the steel rollers was $430 \mathrm{~mm}$ (Figure 4). The load was applied through a circular steel ram with a diameter of $100 \mathrm{~mm}$ adjusted to the centerline of the slab. The loading rate was $1.5 \mathrm{~mm} / \mathrm{min}$ following the method presented in [12]. The test was stopped when the measured mid-span deflection of the concrete slabs reached approximately several millimeters. This test was 
conducted to investigate the effect of combined steel fiber and crumb rubber on the static test results of slabs with different percentages of crumb rubber as green material with enhanced energy absorption capacity, as previously reported [7].

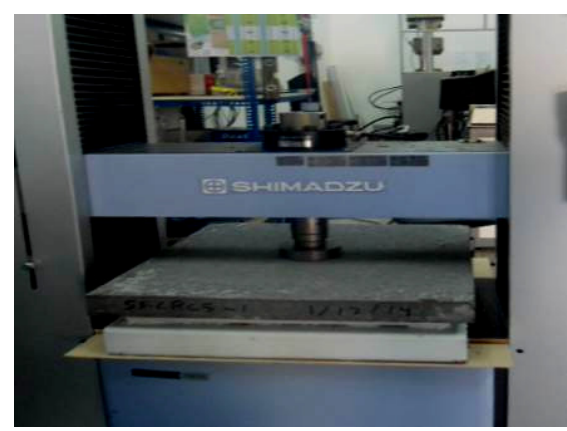

Fig. 3. Flexural test of concrete slabs.

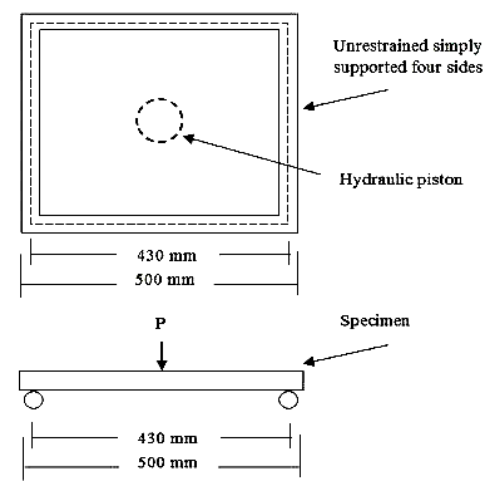

Fig. 4. Test set-up of the concrete slabs.

\section{RESULTS AND DISCUSSIONS}

\section{A. Compressive strength}

The results of the compressive strength tests of different concrete cubes for 28 days are presented in Figure 5. The compressive strength decreased with the increase of crumb rubber ratio. The combined effect of steel fiber and crumb rubber limited this reduction. However, the tendency of a small amount of hooked-end steel fiber $(0.5 \%$ by volume) to improve the compressive strength could be ignored. The compressive strengths of SFCR17.5, SFCR20, and SFCR22.5 were reduced by $21 \%, 25 \%$, and $27 \%$, respectively, compared with SFC.

\section{B. Flexural behavior of beams}

The flexural performance of the concrete mixtures was assessed in terms of the first crack load, first crack strength, ultimate flexural load, ultimate flexural strength (MOR), midspan deflection at maximum loads, flexural stiffness, and flexural toughness, according to the four-point bending test. The typical load-deflection curves of the different concrete mixtures with varying percentages of crumb rubber aggregate are shown in Figures 6 (a) and (b). The averages of three fourpoint bending tests of loading and stresses for each batch are presented in Table V. The load-deflection curves showed that the maximum load that can be sustained by the rubberized concrete is generally lower than that of non-rubberized concrete (whether with or without steel fiber). This reduction is similar to the results from the compressive loading tests. By contrast, the reduction rate in the flexural loads is smaller than that of the compressive loads. The curves for the rubberized concrete present a load-deflection capacity with the same shape. The load capacity declined with the increased content of crumb rubber aggregate in the concrete mix, but the increase in crumb rubber led to a more ductile behavior by increasing the deflections before failure. The shape of the curves for rubberized steel fiber concrete became less sharp than that of the original mix with only steel fiber. This result was also observed in [13], where it was reported that the crumb rubber does not affect the post-peak resistance capacity offered by the steel fiber.

An enhancement of the deflection measured up to failure was obtained with the increase of rubber aggregate particles in the fibrous cement composites (Table VI). Maximum deflection was observed at $20 \%$ content of crumb rubber for plain concrete mixes. A similar trend was observed for the rubberized steel fiber concrete mixes. The increase in the deflection capacity at ultimate load, which is defined as the strain capacity [13], indicates an increase in the deformability of rubberized concrete. The cumulative effect of steel fiber and crumb rubber was confirmed through the enhanced ductility and reduced cracking caused by steel fiber [14]. Therefore, additional restrain of cracks is provided by the presence of crumb rubber particles [15]. A similar trend was observed in the interaction between recycled and industrial steel fiber and rubber granulates [16]. According to ASTM C1018 [17], the first crack load is defined as the point on the load-deflection curve where the tendency of the curve changes from linear to nonlinear behavior, and the first crack deflection is the deflection value that is related to this load. The first crack strength was calculated based on the load obtained at first crack for different mixtures. The effect of crumb rubber incorporation on the first cracking strength is shown in Figure 7(a). First cracking strength decreased by $18 \%$ because of the partial replacement of fine aggregate sand by recycled crumb rubber particles. The combined effect of steel fiber is to minimize the reduction in the first cracking strength. Crumb rubber did not enhance the first crack deflection. The partial replacement of $20 \%$ of the fine aggregate with crumb rubber resulted in the $30 \%$ enhancement of the first cracking deflection compared with PC. This tendency could be attributed to the effect of crumb rubber, which could be neglected in the presence of hooked-end steel fiber with relatively high aspect ratio. Figure 7(b) also shows that the crumb rubber content had an evident effect, that is, the ultimate strength of concrete (plain or fiber) decreased with the increase in rubber ratio. The reduction rate increased from $16 \%$ to $22 \%$ by partial substitution of fine aggregate with crumb rubber in steel fiber reinforced concrete. This trend of systematic reduction was reported because of the lack of pairing between the cement paste and the rubber aggregate [4].

Flexural stiffness $\mathrm{K}$ was also determined from the flexural behavior of the concrete beams (Table VI). $\mathrm{K}$ is presented as the linear part of the load-deflection curve of rubberized 
concrete between $50 \%$ and $10 \%$ of the ultimate load $[18,19]$. The reduction in stiffness of concrete indicates an increase in deformability, which facilitates the enhancement of the capacity of concrete sections to absorb more energy and exhibit better ductile behavior when subjected to high loading rate. Toughness, which was determined by calculating the area under the load-deflection curves up to failure, was observed to be enhanced considerably in the presence of crumb rubber (Table VI). The rates of increase were $28.8 \%, 31.1 \%$, and $26.4 \%$ at $17.5 \%, 20 \%$, and $22.5 \%$ crumb rubber content, respectively. These values indicate that the flexural toughness of rubberized concrete beam is sensitive to rubber ratio. Toughness increases by increasing rubber content. Further replacement of fine aggregate by crumb rubber reduced the toughness values. Thus, optimum results were obtained at $20 \%$ $\left(50.3 \mathrm{~kg} / \mathrm{m}^{3}\right)$. A similar trend was observed in [20] where the highest fracture energy value was recorded at $25 \%$ replacement of coarse aggregate by chipped tire rubber. Reduced fracture energy was observed beyond this ratio. However, rubber aggregate improve the concrete deformability by reducing the local stresses occurred around the microcracks [3]. Thus, a weakness occurred in the rubberized cement composite under loading, causing detrimental to the energy absorbed [20]. Toughness values are also presented in Table VI. It is clear that all rubberized steel fiber concrete mixes exhibited the highest toughness results compared with the other samples. The enhancement was due to the increase in the peak deflection capacity due to inclusion of rubber aggregate from waste tires in concrete. Higher toughness generally offers an excellent property for civil engineering materials for sound barriers and paving constructions [21].

TABLE V. RESULTS OF FLEXURAL LOADS AND STRENGTH OF BEAMS

\begin{tabular}{|c|c|c|c|c|}
\hline Mix & $\begin{array}{c}\text { First } \\
\text { crack } \\
\text { load } \\
\text { (N) }\end{array}$ & $\begin{array}{c}\text { Ultimate } \\
\text { flexural } \\
\text { load } \\
\text { (N) }\end{array}$ & $\begin{array}{c}\text { First } \\
\text { crack } \\
\text { strength } \\
\text { (MPa) }\end{array}$ & $\begin{array}{c}\text { Ultimate } \\
\text { flexural } \\
\text { strength } \\
\text { (MPa) }\end{array}$ \\
\hline PC & 15569 & 15569 & 4.60 & 4.60 \\
\hline SFC & 15856 & 16684 & 4.75 & 4.95 \\
\hline CR17.5 & 12491 & 13275 & 3.74 & 3.92 \\
\hline CR20 & 12110 & 12933 & 3.63 & 3.81 \\
\hline CR22.5 & 11950 & 12671 & 3.58 & 3.75 \\
\hline SFCR17.5 & 13694 & 14030 & 4.11 & 4.15 \\
\hline SFCR20 & 13557 & 13752 & 4.06 & 4.13 \\
\hline SFCR22.5 & 12743 & 12925 & 3.82 & 3.87 \\
\hline
\end{tabular}

TABLE VI. DEFLECTIONS, STIFFNESS AND TOUGHNESS OF CONCRETE BEAMS UNDER FLEXURE

\begin{tabular}{|c|c|c|c|c|}
\hline Mix & $\begin{array}{c}\text { First crack } \\
\text { deflection } \\
(\mathbf{m m})\end{array}$ & $\begin{array}{c}\text { Maximum } \\
\text { mid span } \\
\text { deflection } \\
(\mathbf{m m})\end{array}$ & $\begin{array}{c}\text { flexural } \\
\text { stiffness } \\
(\mathbf{k N / m m})\end{array}$ & $\begin{array}{c}\text { Toughness } \\
\text { (kN.mm) }\end{array}$ \\
\hline PC & 1.07 & 1.07 & 14.18 & 7.048 \\
\hline SFC & 0.80 & 1.41 & 19.45 & 16.032 \\
\hline CR17.5 & 1.35 & 1.51 & 9.05 & 9.086 \\
\hline CR20 & 1.40 & 1.55 & 8.87 & 9.243 \\
\hline CR22.5 & 1.39 & 1.54 & 8.69 & 8.913 \\
\hline SFCR17.5 & 0.81 & 1.80 & 17.21 & 20.576 \\
\hline SFCR20 & 0.82 & 1.83 & 16.91 & 21.343 \\
\hline SFCR22.5 & 0.83 & 1.78 & 15.94 & 20.331 \\
\hline
\end{tabular}

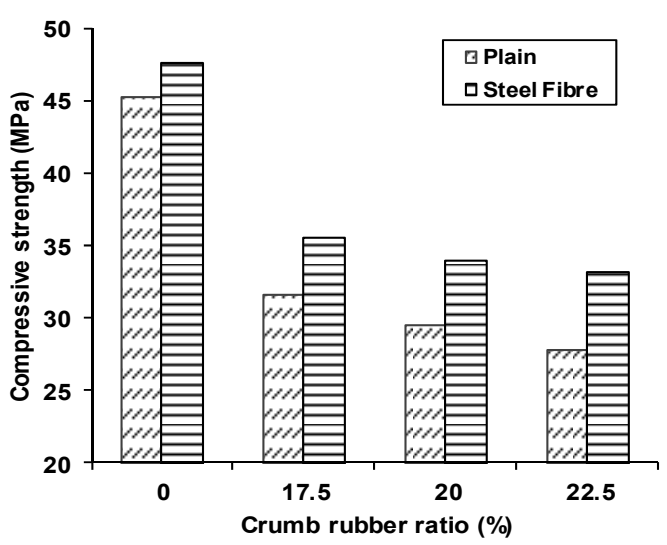

Fig. 5. Compressive strength results.

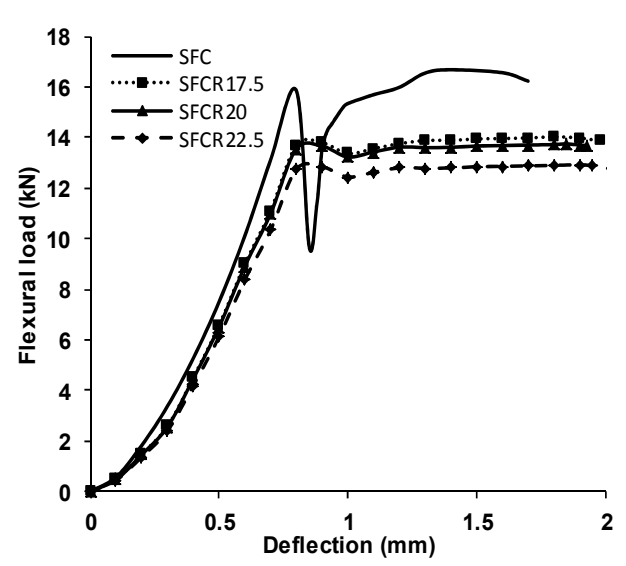

(b)

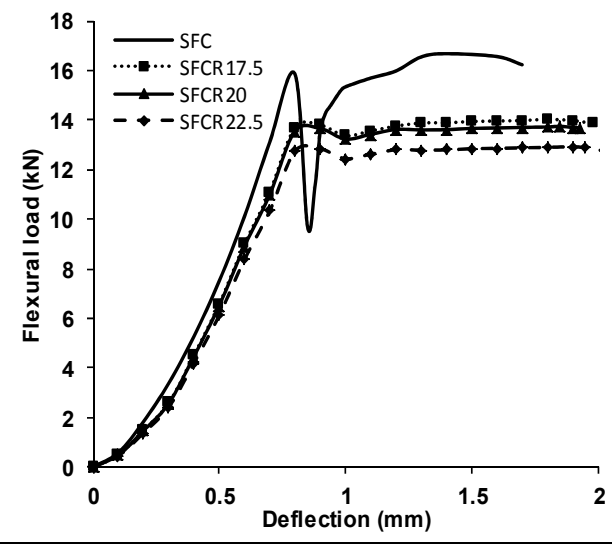

Fig. 6. Load - deflection curves of beams (a) rubberized, (b) steel fiber rubberized concrete.

\section{Flexural behavior of slabs}

Table VII presents the average test results for slabs of each mixture. Flexural test results of slabs are also presented as load-deflection curves in Figures 8(a) to 8(h). All tested rubberized steel fiber concrete specimens had similar loaddeflection trends with a linear branch until the ultimate load was reached and then a descending branch with softening in strain. Scattering was observed in the descending branch, 
which can be attributed to the distribution of fiber in the cracked portions at the post-peak load [8]. The curve for the rubberized steel fiber concrete slabs showed a higher descending slope than the plain rubberized slab because of the presence of steel fiber. The rubber aggregate increased the ultimate defection capacity up to a specified replacement ratio $(20 \%)$. Further increase in ratio resulted in lower values for the slope in the post-cracking phase. This phenomenon could be explained by the weakness in the matrix of slabs produced by further rubber replacement. The bridging effect of crumb rubber fiber is not provided at this stage. The increase in the concrete strength could lead to an increase in the energy absorption capacity [12]. However, rubberized mixes, with or without fiber reinforcement, exhibited reduced ultimate load and increased strain capacity [13]. Moreover, rubber mixes tended to exhibit reduced elastic stage compared with PC or SFC slabs. This finding was also previously reported and attributed to the lower tangential elastic modulus of the rubbercrete slabs [22]. Further studies on the combined effect of steel fiber and crumb rubber aggregate with long rubber fiber should be conducted. Thus, the bridging action could be duplicated and the post-cracking deflection capacity could be enhanced.

The rubber aggregate has a considerable effect on the toughness of concrete slabs (Figures 9 a and b). Table VII shows that the energy absorption capacity (toughness) of concrete slabs increased, with rates of increase of approximately $17 \%, 20 \%$, and $15 \%$ at $17.5 \%, 20 \%$, and $22.5 \%$ replacement ratios, respectively. A minimum of $15 \%$ enhancement of toughness was noted, although a decrease in toughness was observed beyond $20 \%$. A similar trend was observed when crumb rubber was combined with steel fiber. The steel fiber with $0.5 \%$ crumb rubber provided the mixtures with initial enhancement of 14 times more than that of PC. Further improvements in the toughness values were achieved by inclusion of crumb rubber. The rates of increase were approximately $16 \%, 19 \%$, and $14 \%$ for the $17.5 \%, 20 \%$ and $22.5 \%$ slabs, respectively, compared with the SFC slabs. This property indicates that utilizing crumb rubber with steel fiber results in lower weight, higher toughness, and better energy absorption capacity before failure of concrete slabs.

In [23], authors presented the combination of steel fiber and crumb rubber to produce layered concrete slabs subjected to impact force by replacing a specified portion of the steel fiber concrete thickness. The results obtained showed a reduction in weight and more energy dissipation in the rubberized steel fiber concrete plates, which acts as a cushion layer to reduce the effects of impact force. Figure 10 (a) and (b) show adequate residual strengths for the four different mixtures, namely, SFC, SFCR17.5, SFCR20, and SFCR22.5, after the test because of the steel fiber that improved the ultimate flexural strength, energy absorption capacity, and ductility. An increase in the mid-span deflection with the increase in the crumb rubber ratio was also observed. This finding indicates enhanced flexural performance by improved Results obtained from flexure test of concrete slabs ductility and energy absorption capacity for the concrete slabs (Figure 11).
TABLE VII. RESULTS OBTAINED FROM FLEXURE TEST OF CONCRETE SLABS

\begin{tabular}{|c|c|c|c|}
\hline Mix & $\begin{array}{c}\text { Ultimate load } \\
\mathbf{( k N )}\end{array}$ & $\begin{array}{c}\text { Maximum } \\
\text { deflection } \\
\text { at middle } \\
\mathbf{( m m )}\end{array}$ & $\begin{array}{c}\text { Toughness } \\
\mathbf{( k N . m m )}\end{array}$ \\
\hline PC & 35.16 & 18.98 & 42.05 \\
\hline SFC & 37.94 & 22.97 & 588.65 \\
\hline CR17.5 & 29.17 & 20.75 & 49.15 \\
\hline CR20 & 28.39 & 21.40 & 50.40 \\
\hline CR22.5 & 27.38 & 20.62 & 48.23 \\
\hline SFCR17.5 & 31.80 & 25.76 & 682.68 \\
\hline SFCR20 & 31.18 & 26.65 & 701.17 \\
\hline SFCR22.5 & 29.82 & 25.61 & 671.95 \\
\hline
\end{tabular}

(a)
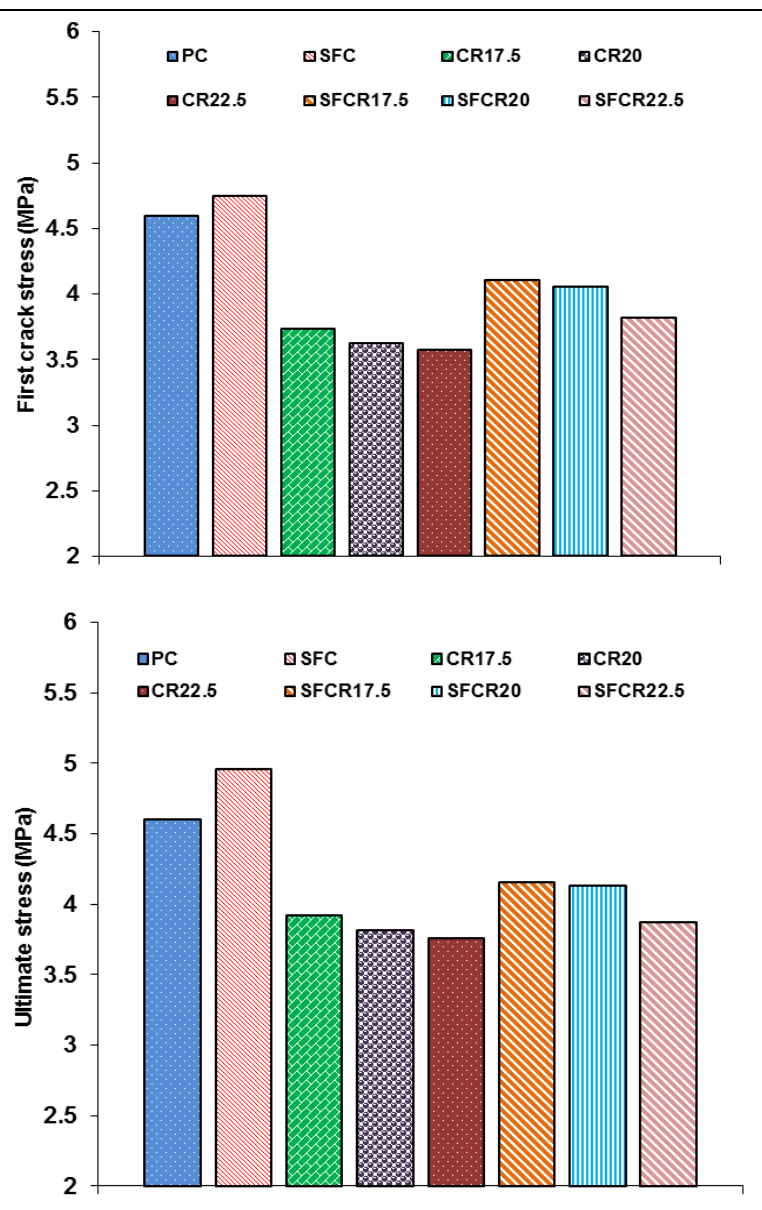

Fig. 7. Flexural strength at (a) first crack, and (b) ultimate strength.

\section{CONCLUSIONS}

In the present study, concrete beams and slabs were prepared by combining hooked-end steel fiber with crumb rubber aggregate to produce a green innovative material with some desirable properties. The concrete beams, whether plain with crumb rubber or steel fiber with crumb rubber, were subjected to four-point bending load. The slabs were subjected to centre point load to investigate their flexural performance. Slump and compressive strength tests were also conducted. The following conclusions were drawn: 


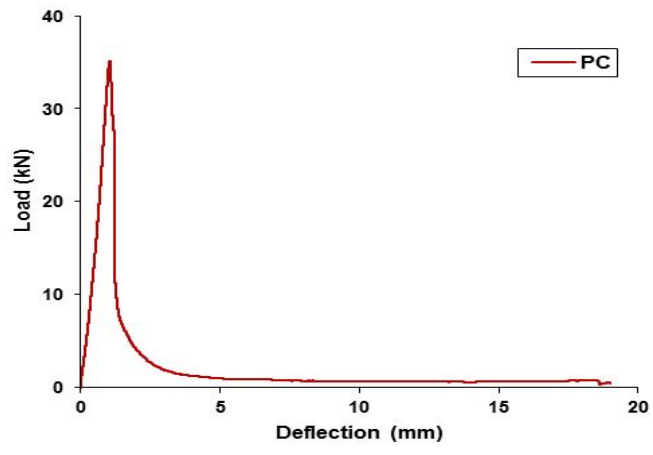

(a) $\mathrm{PC}$

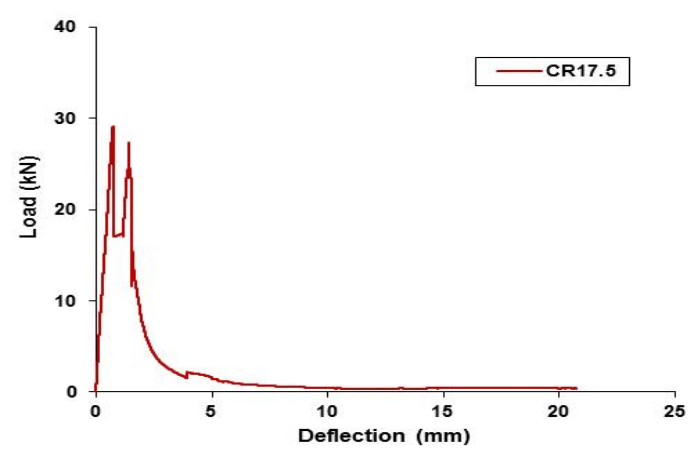

(b) CR17.5

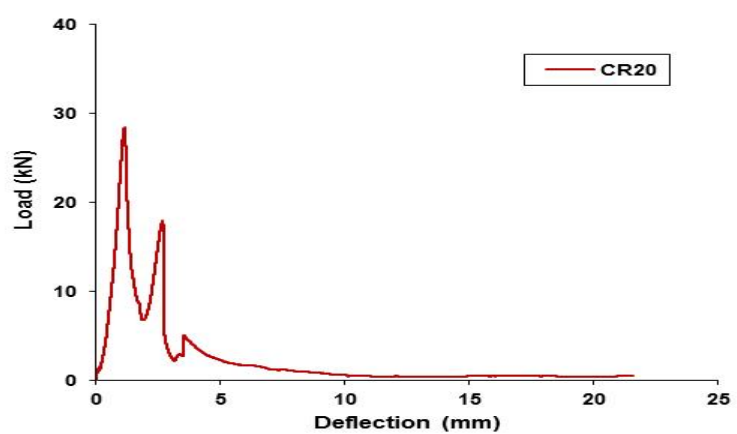

(c) CR20

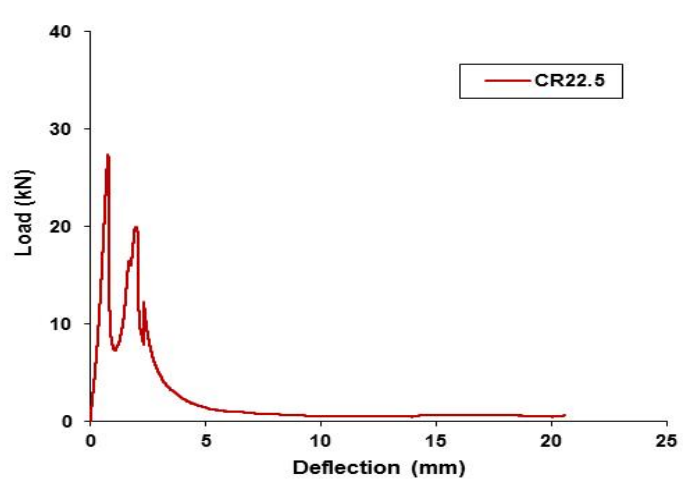

(d) CR22.5

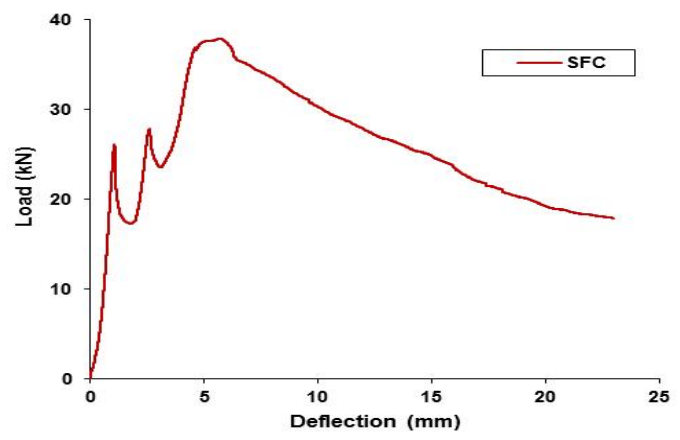

(e) SFC

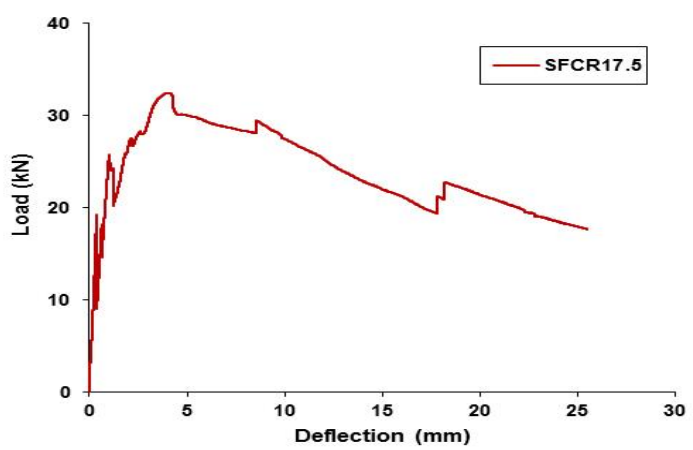

(f) SFCR17.5

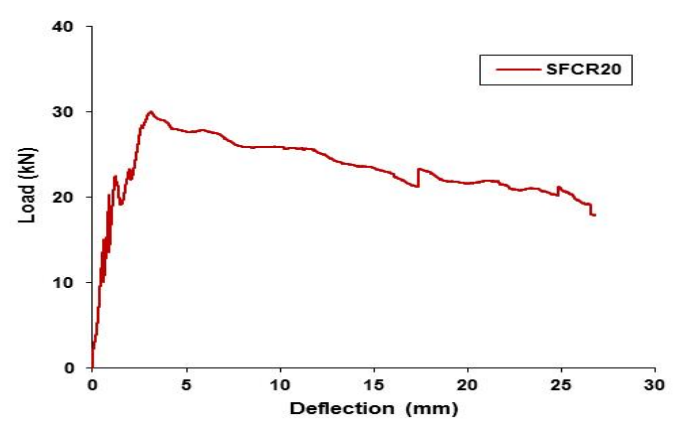

(g) SFCR20

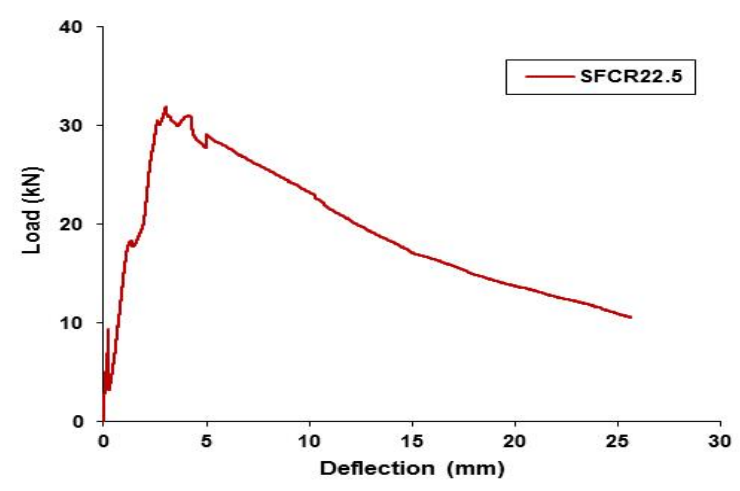

(h) SFCR22.5

Fig. 8. Load - mid span deflection graphs for concrete slabs. 


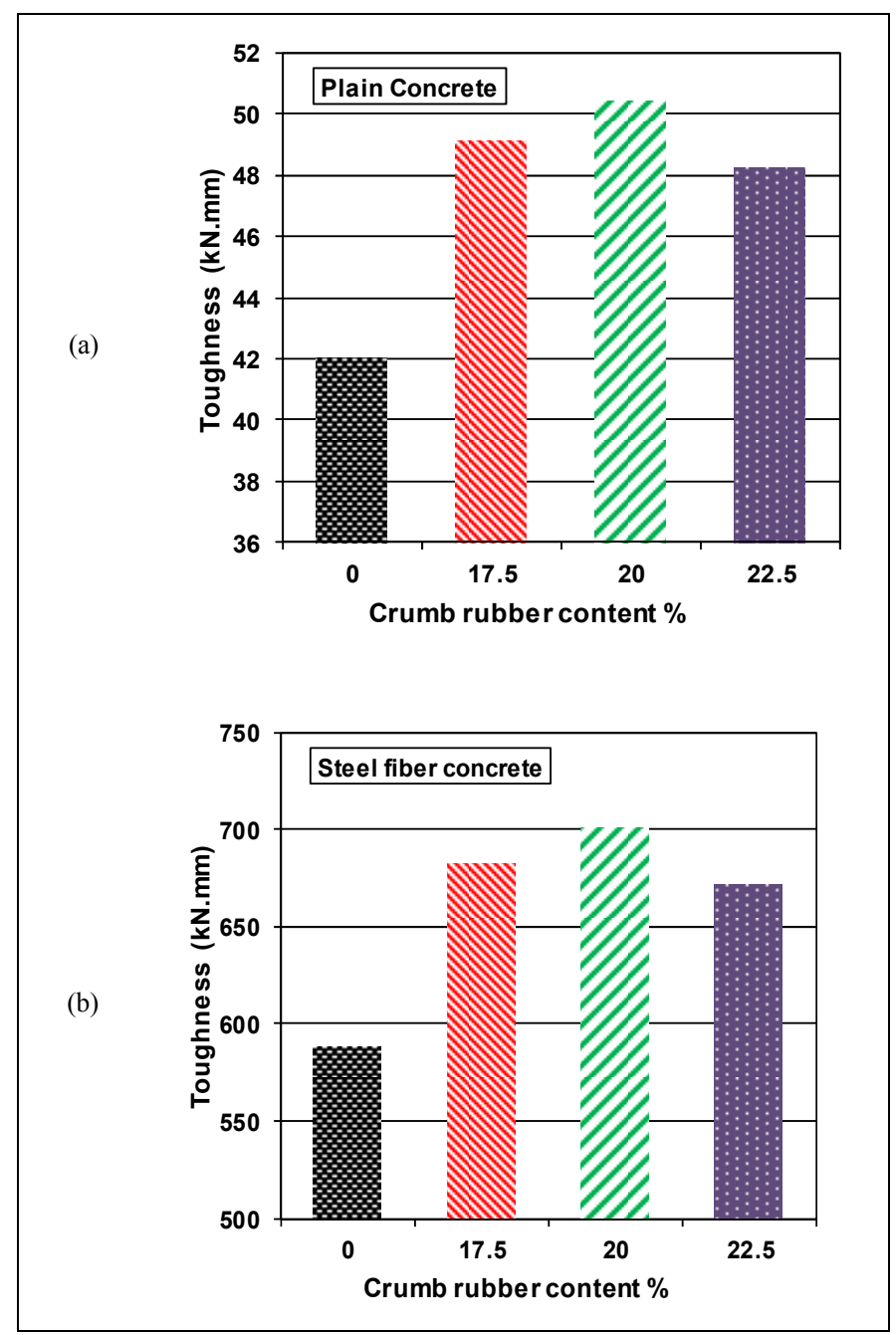

Fig. 9. Effect of crumb rubber inclusion on toughness of concrete slabs (a) plain concrete, and (b) steel fiber concrete.

- The compressive strength of all rubberized mixtures decreased with the increase in the partial substitution of crumb rubber aggregate in plain or steel fiber concrete. The loss of compressive strength values was not less than $20 \%$.

- The inclusion of crumb rubber into the concrete mixtures, with or without fiber, resulted in reduced flexural strength at first crack and ultimate failure for concrete beams under four-point bending load.

- By contrast, toughness, which was determined by calculating the area under the load-deflection curves up to maximum deflection, improved significantly in the presence of crumb rubber. The optimum replacement ratio of sand aggregate by recycled crumb rubber aggregate was $20 \%$.

- All rubberized steel fiber reinforced concrete mixes exhibited the highest toughness values compared with the other samples in this study. The enhancements were due to the lower reduction in load and the increase in the ultimate deflection capacity.

- The ultimate deflection values increased as the crumb rubber ratio increased. In addition, better flexural performance and improved concrete slab bendability before failure were observed when steel fiber was incorporated into the concrete mixture.

- The post-cracking behavior of the rubberized concrete slabs could induce more ductile behavior with the increase in the waste tire crumb rubber aggregate ratio up to $20 \%$. A significant increase in toughness of approximately 16 times was observed for the SFCR20 mixture compared with PC.

- The experimental results showed a promising application of steel fiber/crumb rubber-reinforced concrete, which requires further studies.

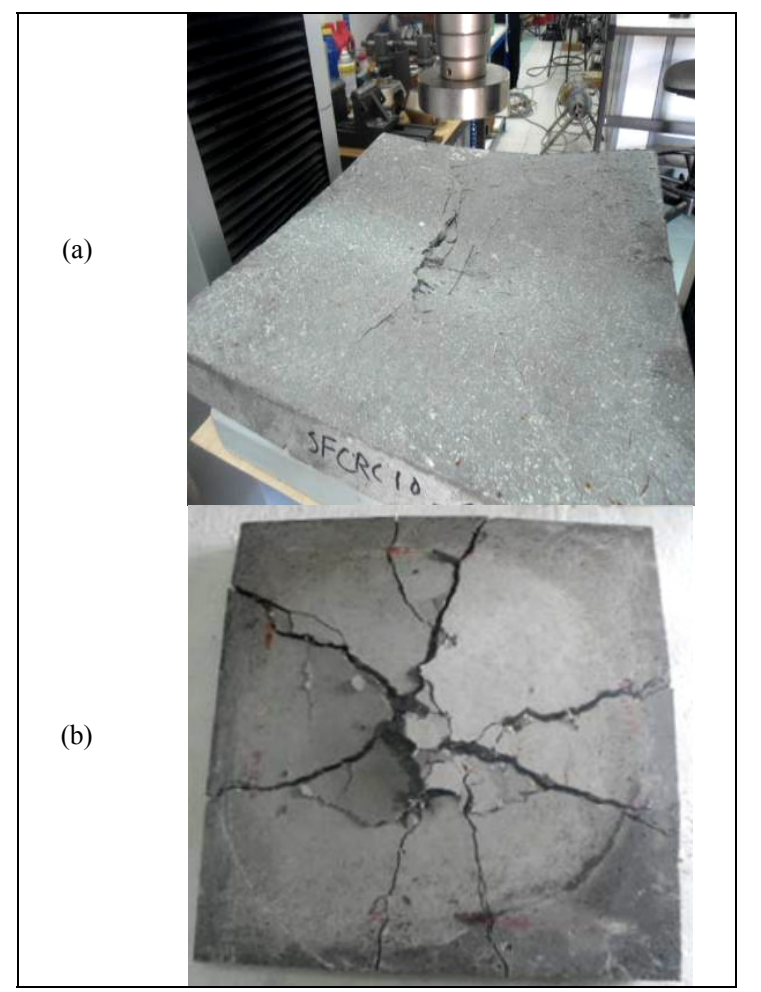

Fig. 10. Failure of concrete steel fiber rubberized concrete slabs under flexural loading. (a) Top (SFCR22.5) (b) Bottom (CSFR22.5)

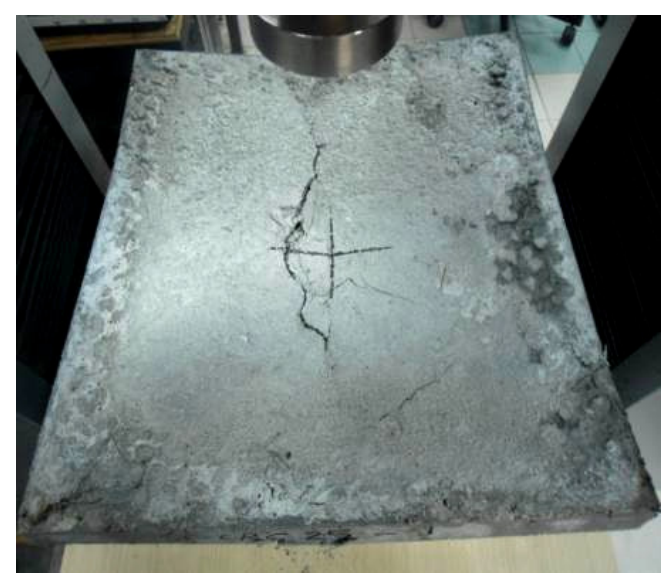

Fig. 11. Failure of steel fiber rubberized concrete (SFCR22.5) 


\section{ACKNOWLEDGEMENTS}

The work presented herein was funded by the Universiti Sains Malaysia grant (Cluster for Polymer Composite: 1001/PKT/8640013).

\section{REFERENCES}

[1] H. Toutanji, "The use of rubber tire particles in concrete to replace mineral aggregates", Cem. Conc. Comp., Vol. 18, No. 2, pp. 135-139, 1996

[2] Z. Ismail, E. Al-Hashmi, "Use of waste plastic in concrete mixture as aggregate replacement", Waste Management, Vo. 28, No. 11, pp. 20412047, 2008

[3] C. Wang, Y. Zhang, Z. Zhao, "Fracture process of rubberized concrete by fictitious crack model and AE monitoring", Comp. Concrete, Vo. 9, No. 1, pp. 51-61, 2012

[4] E. Ganjian, M. Khorami, A. Maghsoudi, "Scrap-tyre-rubber replacement for aggregate and filler in concrete", Const. Build. Mats., Vo. 23, No. 5, pp. 1828-1836, 2009

[5] M. Bekhiti, H. Trouzine, A. Asroun, "Properties of Waste Tire Rubber Powder", Eng. Technol. Appl. Sci. Res., Vol. 4, No. 4, pp. 669-672, 2014

[6] K. Najim, M. Hall, "Workability and mechanical properties of crumbrubber concrete", Proc. of the ICE - Const. Mats., Vol. 166, No. 1, pp. $7-17,2013$

[7] J. Xue, M. Shinozuka, "Rubberized concrete: A green structural material with enhanced energy-dissipation capability", Const. Build. Mats., Vo. 42, pp. 196-204, 2013

[8] G. Centonze, M. Leone, M. Aiello, "Steel fibers from waste tires as reinforcement in concrete: A mechanical characterization", Const. Build. Mats., Vo. 36, pp. 46-57, 2012

[9] D. Flores-Medina, N. Flores Medina, F. Hernández-Olivares, "Static mechanical properties of waste rests of recycled rubber and high quality recycled rubber from crumbed tyres used as aggregate in dry consistency concretes", Materials Struct., Vol. 47, No. 7, pp.1185-1193, 2013

[10] British Standards Institute (BS), Method for determination of compressive strength of concrete cubes, BS 1881:116, London, 1983

[11] American Society for Testing and Materials (ASTM), Standard test method for flexural performance of fiber-reinforced concrete (using beam with third-point loading), ASTM C1609-12, ASTM International, West Conshohocken, PA, 2012

[12] A. Khaloo, M. Afshari, "Flexural behaviour of small steel fiber reinforced concrete slabs", Cem. and Concrete Comp., Vo. 27, No. 1, pp. 141-149, 2005

[13] A. Turatsinze, J. Granju, S. Bonnet, "Positive synergy between steelfibers and rubber aggregates: Effect on the resistance of cement-based mortars to shrinkage cracking", Cem. Conc. Resch., Vol. 36, No. 9, pp. 1692-1697, 2006

[14] R. Olivito, F. Zuccarello, "An experimental study on the tensile strength of steel fiber reinforced concrete", Composite Part B: Eng., Vol. 41, No. 3, pp. 246-255, 2010

[15] A. Turatsinze, S. Bonnet, J. Granju, "Mechanical characterisation of cement-based mortar incorporating rubber aggregates from recycled worn tyres", Build. Envt., Vol. 40, No. 2, pp. 221-226, 2005.

[16] D. Bjegovic, A. Baricevic, S. Lakusic, D. Damjanovic, I. Duvnjak, "Positive interaction of industrial and recycled steel fibers in fiber reinforced concrete", J. of Civil Eng. Manag., Vo. 19, (sup1), pp. 50-60, 2013

[17] American Society for Testing and Materials (ASTM), Standard test method for flexural toughness and first-crack strength of fiber-reinforced concrete (using beam with third-point loading), ASTM C1018-97, ASTM International, West Conshohocken, PA, 1997

[18] A. Turatsinze, M. Garros, "On the modulus of elasticity and strain capacity of self-compacting concrete incorporating rubber aggregates", Res. Conserv. Recy., Vol. 52, No. 10, pp. 1209-1215, 2008
[19] K. Najim, M. Hall, "Mechanical and dynamic properties of selfcompacting crumb rubber modified concrete", Const. Build. Mats., Vol. 27, No. 1, pp. 521-530, 2012

[20] M. Reda Taha, A. El-Dieb, M. Abd El-Wahab, M. Abdel-Hameed, "Mechanical, fracture, and microstructural investigations of rubber concrete", J. of Materials in Civil Eng., Vol. 20, No. 10, pp. 640-649, 2008

[21] T. C. Ling, "Effects of compaction method and rubber content on the properties of concrete paving blocks", Const. Build. Mats., Vol. 28, No. 1, pp. 164-175, 2012

[22] B. Mohammed, "Structural behavior and $\mathrm{m}-\mathrm{k}$ value of composite slab utilizing concrete containing crumb rubber", Const. Build. Mats., Vol. 24, No. 7, pp. 1214-1221, 2010

[23] P. Sukontasukkul, S. Jamnam, M. Sappakittipakorn, N. Banthia, "Preliminary study on bullet resistance of double-layer concrete panel made of rubberized and steel fiber reinforced concrete", Materials Struct., Vol. 47, No. (1-2), pp. 117-125, 2013 